\title{
PSA Level Less than Fifty
}

National Cancer Institute

\section{Source}

National Cancer Institute. PSA Level Less than Fifty. NCI Thesaurus. Code C136611.

A blood concentration of prostate specific antigen less than or equal to $50 \mathrm{ng} / \mathrm{mL}$. 